either as an anaphylactic reaction to cow's milk (as suggested by Parish et al., 1960) or as part of a generalized neural spasm mediated through the autonomic nervous system (Stowens, 1957) precipitated by the spilling of stomach contents or secretions into the larynx, the irritability of which is possibly increased by hypocalcaemia. Handforth (1959) produced fatal respiratory arrest in rats by a temporary (70 seconds) blockage of the airway. Post-mortem examination showed intrathoracic petechial haemorrhages, pulmonary congestion, and oedema, the changes resembling those found in children dying with "typical" cot death. The presence of mild infection of the upper respiratory tract predisposes to regurgitation; this could explain the preponderance of cases in the overcrowded homes and in the winter months and the preceding history of trivial symptoms. Nevertheless, despite the uniform pattern in our typical group, we realize that no one theory fits all the facts, and the problem remains open.

\section{Summary}

Investigation has been made of 122 instances of sudden unexpected death in infancy and young childhood occurring in a fourteen-year period in the Hartlepools-an annual incidence of 9 per 100,000 population.

In three-quarters of these children certain characteristic findings were present which, however, gave no indication of the cause of death, and in half of this group there was no history of preceding illness. Investigation of the background of these deaths suggests a relation to the season of the year, the social grade of the parents, the birth weight of the child, and the size of the family; there is also a striking incidence in members of a twin pair.
The mechanism of death in the children where this remains unexplained is briefly discussed.

We thank Mr. Norman Graham, H.M. Coroner to Stockton Ward, for permission to publish details of these cases; the Medical Officers of Health for the County of Durham, Hartlepool, and West Hartlepool for information concerning infant life and death in their areas ; Dr. A. R. Evans, of Wigan, and Dr. T. A. Harper, of Manchester, for details of their pairs of twins; and the laboratory staff, past and present, at this hospital for their help in these investigations. We have also appreciated helpful correspondence with Dr. R. Ainsworth and the late Dr. A. M. Barrett, of Cambridge, and Dr. J. L. Emery, of Sheffield. We are grateful to Mrs. A. Truefitt for constant secretarial assistance.

\section{REFERENCES}

Adelson, L., and Kinney, E. R. (1956). Pediatrics, 17, 663. Banks, A. L. (1958). Mth. Bull. Minist. Hlth Lab. Serv., 17, 182. Barrett, A. M. (1954). In Recent Advances in Paediatrics, edited by D. Gairdner, p. 301. Churchill, London.

Bodian, M., and Heslop, B. (1956). Eighth International Congress of Paediatrics, Abstract p. 91.

Coe, J. I., and Hartman, E. E. (1960). F. Pediat., 56, 786.

Elliott, R. I. K. (1961). Postgrad. med. F., 37, 616.

Gardner, A. M. N. (1958). Quart. 7. Med., 27, 227.

Handforth, C. P. (1959). Canad. med. Ass. 7., 80, 872.

Jones, H. M., and Camps, F. E. (1957). Practitioner, 178, 223.

Mann, T. P. (1961). Postgrad. med. 7., 37, 620.

Parish, W. E., Barrett, A. M., Coombs, R. R. A., Gunther, M., and Camps, F. E. (1960). Lancet, 2, 1106.

Smith, F. B., and Cooke, R. T. (1948). Ibid., 1, 425

Stowens, D. (1957). Amer. F. Dis. Child., 94, 674.

Swinscow, D. (1951). Brit. med. f., 2, 1004.

Valdes-Dapena, M. A., Eichman, M. F., and Ziskin, L. (1963). F. Pediat., 63, 290.

- and Hummeler, K. (1963). Ibid., 63, 398.

\title{
Management of the Chronic Neurological Patient*
}

\author{
DENIS WILLIAMS, $\dagger$ C.B.E., M.D., D.SC., F.R.C.P.
}

The neurological patient himself rather than his disease is our present subject. In any one family doctor's practice there are not at any one time many purely neurological disorders, but when they do arise they comprise worrying problems of a special nature, they often present a major threat to the patient's future, and they tend to be prolonged. Most acute neurological disorders seen in day-to-day practice are mild, as is for instance the local neuritis caused by the pressure of a disk lesion or by a virus infection, and as is usually vertigo or migraine. Many of the severe disorders may start acutely as a stroke, a fit, or the onset of paralysis, while the subsequent course of the illness may be a slow one, either for better or for worse. Our present concern is for the management of patients with long-lasting disorders which may have had a sudden or gradual onset, and which may improve, may persist unchanged, or may deteriorate. There are, for instance, the cerebrovascular accidents with a long course towards improvement, in contrast to motor neurone disease, where over a couple of years or so

\footnotetext{
- From the Pfizer Lecture delivered to the West London Faculty of the College of General Practitioners on 14 April 1964.

† Neurological Physician, St. George's Hospital, London; Physician, the National Hospital, Queen Square, London.
}

there is remorseless deterioration; there may be the fluctuating course downhill of demyelinating disease, the continuous disability of a congenital hemiplegia or of a chronic traumatic paraplegia, or the episodic course of epilepsy. Not only are the disorders seen to be very varied, but the boundaries of clinical neurology are also very wide, and its application to the patient necessarily involves many other aspects of medicine and of surgery too.

The management of the chronic neurological patient must be based upon the nature of the disorder of function he experiences as well as upon the kind of disease; for though diagnosis is of first importance it is the disability which concerns the patient. Generally, the problems of diagnosis have occupied the physician in hospital, while the family doctor is more occupied with modifying the effects of the consequent disability. Equally, the kind of patient he is trying to help and his attitude to his disability may matter more to the family doctor than the pathological nature of the disease which is causing the chronic handicap. Not only are the patient's personality characteristics which determine his attitude to his disorder important, but his background, which is influenced by the level of his education, by his family milieu, and by his social and economic contacts, contributes for better or for worse to the ease with which he 
can adapt to his disability and with which he can use what function remains.

\section{Kind of Disability}

It is a feature of neurological disorder that handicaps are rarely unitary, for the nervous system so governs all bodily functions that even one discrete lesion may produce many disturbances of efficiency, seemingly distinct to the patient. An obvious example of that is the paraplegia which will cause, among other things, painful flexor spasms, unsteadiness in walking, incontinence of urine, and constipation. We are apt to forget that, although these symptoms together conjure up a clear clinical picture to us, to the patient they are separate and apparently unrelated disorders of function, each requiring management.

The most common disability is disorder of voluntary movement or of bodily control, varying in extent and intensity, and sometimes associated with involuntary movements. It is a distressing feature of these disturbances of movement that generally the disability is less evident when the patient is not trying to conceal his disorder than when he is doing his best to appear normal. This is obviously the case in a patient who has had poliomyelitis and who notices the weakness of a limb most when he is trying his best, but it is also true of the involuntary movements of athetosis, which may be absent at rest, increased when the patient moves, and worst when he tries to control them. The second kind of disability, usually associated with disturbance of movement, is disorder of sensation with reduction or loss of feeling, distortion of sensation, or pain. Finally, and most disastrously, there are the disorders of mind reflected in disturbance of intellect or of behaviour. In these cases the disorder may quite evidently be due to deprivation of function as in amentia or dementia, but it may also include distortion of normal behaviour as in the aggressive psychopath and in many of the epilepsies. When a number of these disorders of function occur together they increase the problem of management in a logarithmic way; although it may be comparatively easy to give a backward child who has a normal temperament a useful place in society, if the backward child also has epilepsy the problems of education and of employment are greatly enhanced, while if with these two handicaps there is also a personality defect the patient may present an almost insoluble social problem.

\section{Progress of the Disability}

It is commonplace that slowly advancing disorders such as peroneal muscular atrophy cause much less economic handicap than conditions of sudden onset such as poliomyelitis for the corresponding degree and extent of weakness; this is because of the extraordinary facility with which the nervous system can make use of residual function, given the time to do so-a facility which is reflected at the social level in the patient's ability to adapt to the handicap. The easiest disorders to help are those which are improving, however slowly the progress is. An example of this is the hemiplegia with aphasia which responds so well to rehabilitation and re-education. In contrast, stationary conditions such as those due to birth injury or post-natal illness present special problems of education and settlement as well as major psychological problems arising from the patient's awareness that he can never be the same as others. There has been improvement in the last few years in the facilities available for helping people with this kind of permanent disability, beginning in early life with the special centres for spastic children, the special paraplegic units, and later the industrial and other rehabilitation centres.

A different group of patients who require special consideration are those with episodic disorders which may from time to time be disastrously crippling, while there are periods of normality between. There are, for instance, patients with epilepsy, trigeminal neuralgia, or neuralgic migraine who must live an otherwise normal life that is interrupted by phases of distress which call for great fortitude. Lastly, there are those disorders whose remorseless deterioration cannot be hidden from the patient, which include Parkinsonism and disseminated sclerosis, but of which the worst example is motor neurone disease. When intellectual deterioration is associated with the advancing physical disability the patient soon loses insight into his deterioration, and the problem then becomes a family-social one rather than personal.

\section{Kind of Patient}

The patient's age affects the management of his disability, for the younger he is the greater is his capacity to adapt, and the greater the opportunities for education and therapeutic benefit. Poor general health restricts the opportunity for management and rehabilitation, while the higher the patient's economic and social status the wider in general are the opportunities to help ; unfortunately for the doctor, these wider opportunities are often accompanied by more unrealistic demands by the patient and his family to try to achieve an unattainable level of restitution of function. Psychological factors are probably more important than physical in determining response to management and treatment, and of these the first is the patient's intelligence, for the higher the intelligence the more educable and responsive is the patient. Of great importance, too, is the patient's attitude to his disability and to the effects of his disability upon his personal life, upon his career, and upon the relationship of others to him. In this there is a two-way traffic which is dependent upon the attitude of his friends, his co-workers, and his family to him and his illness. It is probable that their solicitude will do more damage than their callous disregard.

The patient's personality traits greatly affect his capacity to overcome his handicap; they determine his adaptability, for instance, and we all recognize the rigid and somewhat meticulous patient of obsessive make-up who finds it impossible to adjust to comparatively minor disabilities which a more phlegmatic person might disregard. Finally, there is the degree of fortitude which the patient shows. At one extreme is the Martha who unconsciously blandishes the effects of her chronic disability, and at the other the patient whose stoical disregard of his handicap leads to the mistaken diagnosis of euphoria. There are more patients with long-lasting neurological disabilities living their stoical lives as though they were unaware of their handicaps than those who disregard them because they cannot see them. Lack of insight is essential to the diagnosis of euphoria, and not to make a critical distinction between the consequences of fortitude and of euphoria may ruin the therapeutic relationship between the doctor and his patient.

\section{Kind of Society}

When a disability has become permanent, overt sympathy must cease, and the patient's family and circle of friends will help best if they learn to respect him in relation to his disability, and if they also respect the use he can make of his remaining function. To encourage him in this is of greater benefit than to adopt a protective and solicitous relationship to him. Many patients cannot help being anxious, but anxiety within the home for the patient's future usually has disastrous consequences; an attitude must be fostered in which philosophical acceptance of the disability and its consequences can be distinguished from callous indifference to them. 


\section{Family Doctor and the Disability}

It is surprising how many family doctors seem reticent in handling neurological disease, for clinical neurology is the reasonable application of elementary anatomy and physiology to the problems of the life of a handicapped person, and it is evident that in our social structure the family doctor should not only be primarily responsible for the patient's welfare but is essential to it. The neurological physician and surgeon may help in diagnosis and in initiating treatment, and he may also play his part in ensuring custodial care or rehabilitation, but after that his task is to advise the family doctor when advice is needed. Ideally, the patient will return to hospital for review at infrequent intervals, and with a proper professional relationship the neurologist working through and with the family doctor may from time to time refer the patient to special clinics or special therapeutic centres. Then the patient must come home ; for his place is at home, and there his main help must come from the family doctor. There is a tendency to-day for society to feel that the chronically handicapped patient is in some way the responsibility of some State organization, but every separation of the patient from his home and his normal environment should in some degree be considered a shortcoming -though perhaps a necessary shortcoming-in management.

\section{Doctor's Relation to the Patient}

The doctor's relation to the patient and to his disability depends upon the duration as well as the severity of the disorder. If long-lasting or stationary there is a lot to do and much to teach the patient and his family.

First, the patient should always be given credit for fortitude. Patients have much more time to consider the nature of their afflictions than have their doctors, who see them a few minutes a week; they resent their disabilities being brushed off, while they gain in self-respect if there is a frank relation with the doctor, with forthright discussion about what he cannot expect to do and what he can do, and the personal consequences of both. There is far too much kindly covering up in the handling of the chronic sick.

Secondly, it should be made quite clear to the patient that it is his disability we are dealing with, and that, though the disability he has may not be his fault, it is his concern. He will be taught that we in the profession and in society at large will do our best to help him, but that the disability and the problem remain his.

Thirdly, he must be taught to have a spirit of independenceindependence of the doctor and of the social and philanthropic organizations within the National Health Service and outside it that are available to help him. He should know help is there, but should learn how and when to use it. Visits to the doctor should be regular but infrequent, and should be made when the patient is well as well as when he is ill. Organizations should be called upon to help for a positive reason, for treatment, rehabilitation, help in employment or with a holiday, and not be regarded as an opiate. Independence includes independence of spirit as well as physical independence of others at home and in work.

Lastly, the patient must be taught that he still has a valuable place in his family and in society, and be encouraged to live as active a life outside his home as is possible in the circumstances. When outside help is needed this is now most easily obtained through the hospital clinic, where the almoners' ${ }^{1}$ department has close contact with the D.R.O., and through him with special centres. Within the State organization these include excellent rehabilitation centres like the one in Camden Town, to which the patient is taken daily from home, or the industrial rehabilitation centres where the patient will live for weeks or months,

${ }^{1}$ Now called the Social Service Department. as he does at Egham, or the special hospitals like the Paraplegic Units at Stoke Mandeville and Pinderfields. The almoner will also make available voluntary organizations such as the National Spastics Associations, the Muscular Dystrophy Society, the Multiple Sclerosis Society, or the British Epilepsy Association; these will be used when necessary but not at other times. The help that is available through channels of this sort may be therapeutic, educational, or material. Material help may sometimes be financial, is often social, and may include the provision of special amenities, including utensils or aids to living. The National Hospital and other hospitals have museums of specially designed implements available for paraplegic and hemiplegic patients as well as for those with other handicaps. No chronically disabled patient should be allowed to live at home until the house has been inspected and he has been taught to make the maximum use of the mechanical aids which are at present so readily available. Repeatedly patients advise us upon these, and so help to improve existing facilities.

When a patient with chronic neurological disease is deteriorating the doctor should treat him actively. There is no disorder which will not seem to respond to treatment, and medical treatment even if intermittent keeps hope alive in face of the evidence. We all know that most patients not only need hope but want to be able to hope, and they welcome hope to the extent of co-operating in its maintenance. There are few patients with motor neurone disease going downhill who will not be benefited by a course of six weekly intramuscular injections of vitamin B with two months' respite and then a repeat, fortified by contact with the doctor or the visiting nurse. The blindness of the intelligent but handicapped patient to his advancing adversity is easily fostered, and this helps the family as much as it helps the patient. Our ability to help the slowly deteriorating patient is also enhanced by his own capacity to adapt to his slowly changing bodily estate. After all, each of us takes the limitations of increasing age as normal for the decade in which we find ourselves. Montaigne wrote: "Observe in all the ordinary changes and declinations we undergo, how nature hides from us the sight of our loss and decay. What remains to an old man of the vigour of his youth and of past days ? I do not believe we should be able to endure such a change if it came upon us all at once; but nature leads us by the hand little by little down a gentle and imperceptible slope, step by step, and so lowers us to it."

In helping these patients it is important to keep the needs of the family to the fore, for there are times in the handling of prolonged illness when the patient should be in hospital for the sake of the family as well as for himself, although as a general rule long-term hospital care should be regarded as an admission of therapeutic defeat and its institution should be decided on positive grounds alone.

When the chronic illness is episodic the patient should be taught to live with his disability but against the evidence it presents. The patient with epilepsy, for instance, should live his life so far as is possible as if he were never going to have another attack, and yet not be too dismayed when there is a recurrence. This is much better than the acceptance of the attacks as a reason to curtail lively activities, for enforced restriction of interests disturbs the patient and aggravates the epilepsy. Whenever there is deterioration in the epileptic natient's state, with increase in the number or the intensity of the attacks, if you have excluded intercurrent physical disease, you should wonder whether the causes of the deterioration are psychological and are closely related to the impact of the attacks on the patient's life pattern.

\section{Management of the Disorder Itself}

This is not the place to dwell upon the details of the use of relaxants, sedatives, tranquillizers, or analgesies, nor can the 
detailed treatment of individual diseases be considered. The importance of the generalizations which have been made on the management of the patient himself is enhanced by the realization that drug treatment of a chronic neurological patient plays a comparatively small part in his total management, and is often, unfortunately, unsatisfactory.

When there is disorder of movement the first rule is to keep the patient active with regular daily exercise, on the bed if necessary, walking preferably, and, ideally, in a swimming-pool. Exercise need never be strenuous, for it is aimed at maintaining mobility of joints and the health of muscles. Far too many patients lie down under the burden of their illness and are encouraged to do so. A few minutes of active endeavour a day are worth a week of " physiotherapy," while the use of active movement with re-education by the physiotherapist transcends the value of all the massage or electrical treatment which might be available to the patient. The maintenance of movement may entail much physical effort and great perseverance ; when locomotion has to be assisted the doctor will find much help from the special departments of hospitals, where the National Health Service provides all that can be made available to keep the patient mobile and, if possible, in assisted employment. Here, too, special knives, forks, and other utensils will be designed and supplied, and advice be given about the fitting of rails, ramps, and pulleys in the home. Appliances and furniture to alleviate the physical and social effects of sphincter disorder will also be provided. When disability is severe enough transport to work will be arranged where possible; and of course sheltered workshops such as those organized by Remploy are available through the D.R.O. Medical social workers know all about this rehabilitative and welfare work, which is readily available to the doctor and his patient.

When sensation is diminished the main problem is attention to skin and pressure points, and to the bladder; but it is remarkable how the body adapts to sensory loss, and how the chronic patient, once he is tided over the onset of his illness, maintains good general health. Intractable pain needs special attention, and a number of centres are available for its relief. In general, sedatives and tranquillizers are most helpful but may be combined with analgesics, and medical relief is usual because surgical intervention is sometimes disappointing and must be reserved for extreme and continuing pain. The three methods of surgical relief are in the section of peripheral nerves or the use of injections of phenol in water, spino-thalamic tractotomy, and now thalamotomy.

Assessment of the intensity of persisting pain is most difficult, and can best be made by the family doctor, who knows the patient well. The hospital worker, who has not this advantage, must rely more on physical signs and on verbal descriptions; all too often he recognizes courage in retrospect, though, like Harold Nicolson, he has known "Those men and women who lie in bed and see the day dawn through the blind, and hear the life of the streets begin again, the sound of some cart moving, the sound of some belated motor changing gear-those men and women who thus' lying know that the dawn means for them another day of pain, another day of fearing the great cycles of pain which wheel inexorably around their bed-those men and women who, knowing this and dreading this, can still keep courage, can still face the grim tyrannies of pain and fear with a derisive smile: those people are my heroes. The people who have time to fear and time to suffer: the people to whom every sunset is red with agony and every dawn is chill with fear. Let us, when faced with sudden tragedy in its most appalling form, remember that no sudden tragedy can be so terrible as one that is prolonged, no courage can be so magnificent as that which knows, which waits, but which can still endure."2

When the physical disability is associated with intellectual deficit the problem may be immense, and the appropriate authority should be notified as soon as possible. If the patient is a child the medical officer of health will provide educational and medical facilities, but he needs time to do so. The earlier he knows about the case the better, because of the difficulty he finds in securing a place in clinics, in special schools, and in institutions. The handicapped child's family should be taught to keep the patient's life routine and simple, and to limit his endeavours to his capacity; for enthusiastic but ill-guided educational training will so readily graft a neurosis upon the pre-existing intellectual deficit. More harm may be done by parents who are anxiously ambitious for their handicapped children than by those who neglect them. The problem of the backward child may be complicated by the appearance of a behaviour disorder, and then it is especially wise to take psychiatric advice early ; for a mentally handicapped patient with a behaviour disorder can quickly disrupt a family, and custodial care should be readily available for the sake of others as well as the patient. First-aid recourse to sedatives without planning the patient's life does more harm than good. The adult who has dementia as a symptom of this chronic disease will finally need custodial care, and in his case, too, how long he can stay at home will depend upon social and family factors, not the least of these being the degree to which his illness is disorganizing the lives of those around him.

These last paragraphs have emphasized that co-operation between the family and the doctor, and between him and the hospital, is essential, and that much enthusiastic help can be made available to the overburdened family doctor when he asks for it. When he does so, the diagnosis and therapeutic techniques and rehabilitative institutions which his letter has made available will be most important to the patient, but it is he who must remain the key figure in an elaborate organization.

' From Cope, The Quiet Art, 1951. 